\title{
LINFOMA NÃO HODGKIN DE GRANDES CÉLULAS B ACOMETENDO CAVIDADE ORAL - RELATO DE CASO
}

Ana Kelly Saraiva Filgueira Sampaio ${ }^{1}$; Ana Larisse Carneiro Pereira ${ }^{2}$; Jéssica de Sousa Noronha ${ }^{3}$; Chantal Candido Cavalcanti ${ }^{4}$; Rodrigo Toscano de Brito ${ }^{5}$; Francisco Paulo Araújo Maia. ${ }^{6}$

Introdução: Os linfomas de células B acometem cerca de $90 \%$ de todos os casos de linfoma. O linfoma difuso de grandes células B é a forma mais comum dos linfomas não Hodgkin e acomete principalmente adultos, mas também se manifestam em crianças, com apenas $2 \%$ localizados na cavidade oral. Objetivos: Relatar o diagnóstico e tratamento de um linfoma não Hodgkin localizado em cavidade oral de paciente pediátrico. Relato de Caso: Paciente do gênero masculino, 07 anos, apresentando aumento de volume em região de maxila posterior direita, com 05 meses de evolução e exame tomográfico evidenciando áreas de reabsorção óssea com acometimento do seio maxilar direito. Para realização do diagnóstico o paciente inicialmente foi submetido a biópsia incisional com remoção dos elementos dentários associados à lesão e resultado histopatológico de lesão linfoproliferativa, confirmando o diagnóstico de Linfoma não-Hodgkin difuso de grandes células B após imuno-histoquímica. Em seguida o paciente foi encaminhado para tratamento quimioterápico e após 01 ano de quimioterapia não apresentava lesões linfoproliferativas. Conclusão: O diagnóstico dos linfomas orais pode ser complicado pelo baixo índice de suspeita clínica. Diante desta condição, é indicada a realização de biópsia incisional, sendo a área de escolha criteriosa para que não ocorram erros diagnósticos. Atualmente, a melhor opção de análise diagnóstica é o exame imuno-histoquímico da lesão, que distingue as condições benignas das malignas, oferecendo uma rigorosa subclassificação dos tipos de linfoma.

Palavras-chave: Cavidade oral. Diagnóstico. Linfoma não Hodgkin.

\footnotetext{
${ }^{1}$ Acadêmica de Odontologia pelo Centro Universitário Doutor Leão Sampaio;

${ }^{2}$ Cirurgiã Dentista pelo Centro Universitário Doutor Leão Sampaio;

${ }^{3}$ Cirurgiã Dentista pelo Centro Universitário Doutor Leão Sampaio;

${ }^{4}$ Acadêmica de Odontologia pelo Centro Universitário Doutor Leão Sampaio;

${ }^{5}$ Mestrando em Implantodontia pela São Leopoldo Mandic;

${ }^{6}$ Mestrando em Cirurgia Buco-Maxilo-Facial pela Universidade de Pernambuco

Autor Correspondente: kelly_sara2011@hotmail.com.
}

3 Id on Line Rev. Mult. Psic. V.12, N. 40. 2018 - ISSN 1981-1179 EDIÇÃO ESPECIAL: I CURSO DE ONCOLOGIA DO CARIRI / II JORNADA DE PESQUISA QUANTI-QUALITATIVA EM ONCOLOGIA. JUAZEIRO DO NORTE, 05 A 10 DE MARÇO DE 2018. Edição eletrônica em http://idonline.emnuvens.com.br/id 